\title{
The Potential Ecological Risk of Cd for Different Benthos in Artificial Reefs
}

\author{
Yuanyuan Dai, Hong Wang, Yan Gao, Chunqiang Hou and Kefeng Liu \\ Tianjin Bohai Sea Fisherise Research Institute Tianjin,China
}

\begin{abstract}
Using Inductively coupled plasma mass spectrometry to detect $\mathrm{Cd}$ in benthos the artificial reef.The results showed that: Cd of benthos is varied from of $0.011-0.541 \mu \mathrm{g} / \mathrm{L}$, mean $0.188 \pm$ $0.220 \mu \mathrm{g} / \mathrm{L}$. The distribution of $\mathrm{Cd}$ decreased in the order: gonads $>$ gills $>$ muscle in different tissues. The enrichment regularity in muscle $\mathrm{Cd}$ of different benthic were Oratosquilla, Crab, Fish, Shrimp, Ocellatus. Its health risk factor is far less than 1, indicating that $\mathrm{Cd}$ has no obvious health risks on exposure population.
\end{abstract}

Keywords-heavy metals; spatial distribution; ecological risk assessment

\section{INTRODUCTION}

In 1993, cadmium has been IARC (International Agency for Research on Cancer, IARC) classified as class I carcinogen (IARC) ${ }^{[1-5]}$. Sunan Jiang study shows that "pain disease" with food or water to cadmium. Cadmium can accumulate and zoom in $\mathrm{vivo}^{[6-8]}$. Marine cadmium in seafood can give the surface of the main contacts, visceral absorption, sediment exposure. Cadmium harmful to the human body, enters the food chain, it is difficult completely metabolized. But on the studies of heavy metals distribution of benthos in artificial reef rarely reported, based on this, the paper of heavy metals in artificial reef about organisms in preliminary accumulation of $\mathrm{Cd}$ and other aspects of ecological risk to the reef area of scientific understanding of heavy metal pollution and its environmental safety for the protection of aquatic ecological effects of the area's ecological safety, scientific development and management of biological resources and the prevention and control risks provide a scientific basis.

\section{MATERIALS AND METHODS}

\section{A. Sample Collection and Determination}

Artificial reef areas selected for the survey area (Figure 1), in which the station is located in the $20101,2,3$ vote reef; 4,5,6 stations located in 2012 voted reef; stations 7,8,9 located in 2014 voted reef; nine were selected sampling stations. Field survey of all processes in strict accordance with "marine monitoring" (GB/T12763.6-2007) [9-10] carried out the job. Selecting a different niche benthosin artificial reef as the object, after dissection, take the muscle was freeze-dried, and then by microwave digestion and then measured on the machine.

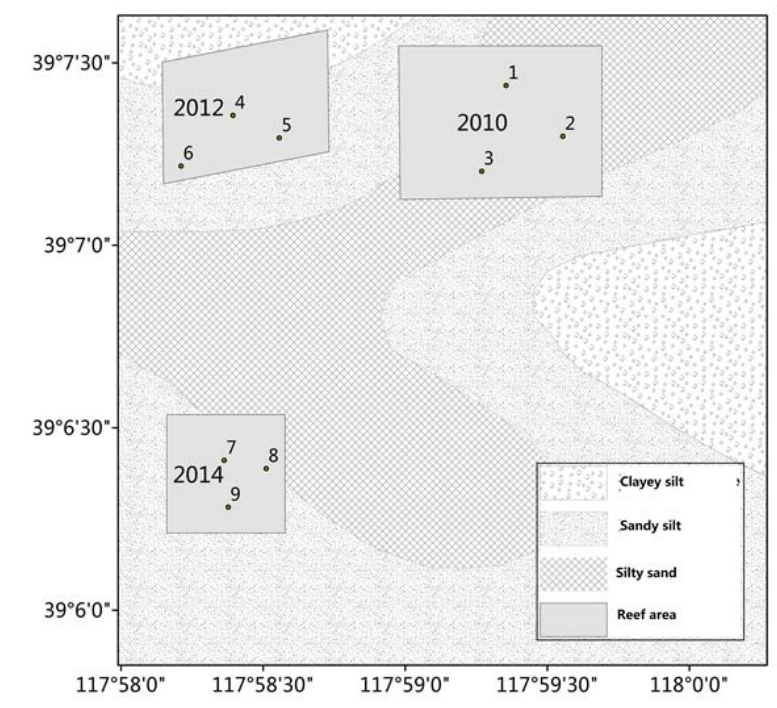

FIGURE I. SAMPLING SITES IN ARTIFICIAL REEFS

\section{B. Enrichment Different Niche Benthic Organisms}

Select different stations benthic organisms (fish, shrimp, crab, octopus and short Oratosquilla) muscle as the research object, by microwave digestion, the measured average concentration of $\mathrm{Cd}$.

\section{Fish Health Risk Assessment}

USEPA established objective risk evaluation system (THQ), evaluation of exposure to chemical pollutants on the population exposed to potential hazards that may exist THQ as a non-cancer risk assessment system, if the result of the calculation is greater than 1 , indicating that the population may be exposed hazards; less than 1 indicates that there is no hazard to exposed populations affect ${ }^{[11]}$.

$$
T H Q=\frac{E_{F} \times E_{D} \times F_{I R} \times C}{R_{F D} \times W_{A B} \times T_{A}} \times 10^{-3}
$$

$E_{F}$ is exposed frequency (365days / year); $E_{D}$ is the time period of exposure is generally the average human life span (70years); $\mathrm{F}_{\mathrm{IR}}$ exposed fish consumption amount of people ( $\mathrm{g} /$ person/day); $\mathrm{C}$ for the heavy metals in fish the actual content $(\mathrm{mg} / \mathrm{kg})$; RFD oral reference dose; WAB is the average body weight $(\mathrm{kg})$; TA non-carcinogenic average exposure time (365days /year $\times \mathrm{ED})$.

D. QC

The accuracy of the test method is close to $10 \%$ within a 
$95 \%$ confidence level, the standard material recovery of $90 \%$.

\section{E. Statistics and Analysis}

All data are used Excel for data processing; SPSS10.0 statistical analysis; GraphPad Prism6and ArcGIS cartographic.

\section{RESULTS}

\section{A. The Enrichment Cd in Muscle of Different Niche Benthic}

The muscle $\mathrm{Cd}$ of different niche benthic in Figure 2. Range of $0.011-0.541 \mu \mathrm{g} / \mathrm{L}$, mean $0.188 \pm 0.220 \mu \mathrm{g} / \mathrm{L}$.

Its enrichment regularity were Oratosquilla, Crab, Fish, Shrimp, Ocellatus. It can be seen, the position occupied by a different niche benthic in the water layer determines the muscle concentration of $\mathrm{Cd}$. The underlying biological, closing the sediment, with higher levels.

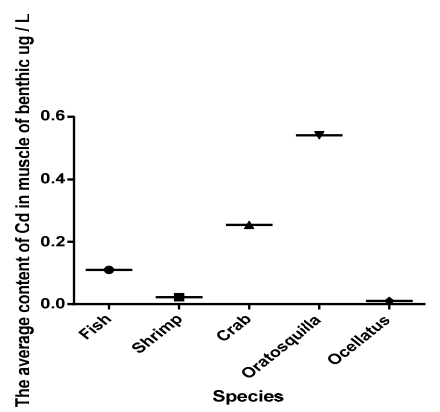

FIGURE II. THE AVERAGE CONTENT IN MUSCLE OF CADMIUM $(\mathrm{MG} / \mathrm{L})$

\section{B. The Enrichment Cd in Different Tissues}

The content of $\mathrm{Cd}$ in tissues in Figure 3. Range of 0.254$1.095 \mu \mathrm{g} / \mathrm{L}$, mean $0.188 \pm 0.220 \mu \mathrm{g} / \mathrm{L}$.

Its enrichment regularity of different tissues for different crustacean weregonads, gills, muscle. It can be seen, Gonads cadmium enrichment is far greater than any other organization because of crustaceans use of gill were filter feeders, so soluble cadmium in seawater absorb higher muscle.

According to USEPA standards ${ }^{[11]}$, an oral reference dose $\mathrm{R}_{\mathrm{FD}} \mathrm{Cd}$ element is $0.001 \mathrm{mg} / \mathrm{kg} /$ day. The average adult body weight $\mathrm{W}_{\mathrm{AB}}$ is $60 \mathrm{~kg}$. The average daily amount of fish for human consumption is $36 \mathrm{~g}$. The health risk factor of $0.004, \mathrm{Cd}$ is much less than 1 , indicating that $\mathrm{Cd}$ exposed populations had no significant health risk.

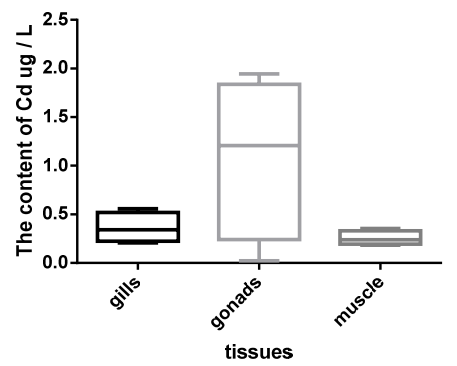

FIGURE III. THE AVERAGE CONTENT IN TISSUES OF CADMIUM (MG/L)

\section{DISCUSSION}

Majority of the industries at coastal area discharge the chemical effluents into the aquatic environment which in turn cause changes in habitat, species distribution, abundance, and bio-geo chemical cycles ${ }^{[1]}$. Wastes from urban, industries, and mining are the potential sources of heavy metal pollution. The distribution of heavy metals in seawater has widely been recognized as a major factor for biological risks ${ }^{[2-5]}$. As the spawning and nursery grounds of many marine organisms, including commercially valuable shrimp and fishes, which are plenty available in estuarine and coastal areas, they are directly affected by such influx of chemical contaminant into the ecosystem ${ }^{[12]}$.

Fishes are on the top of the aquatic food chain and accumulate large amounts of metals from water and sediment. Studies from field and laboratory experiments show that accumulation of heavy metals in tissues of animals depends mainly on metal concentration present in water. Because metals are taken-up by filter feeders ${ }^{[8]}$.

Our study reported that the accumulation of Cd (Less than or equal to 0.1$)^{[13]}$ were exceeding the maximum permissible limit and the study stations in different tissues might face high level risk from metal pollution in the future. In aquatic ecosystems, fishes are considered as good representative indicators of the overall system of health, due to their relatively higher position occupied in the food-chain. Marine organisms, including fish, accumulate heavy metals through direct absorption, or via food chain, and pass them to human beings by consumption, causing acute chronic or disorders. Numerous reports describe the accumulation of metal residues in wild marine fish species.

The European Food Safety Autority (EFSA) ${ }^{[6]}$ has established regulatory guidelines regarding dietary mercury, cadmium intake. It recommends a PTWI of $7 \mathrm{lg} / \mathrm{kg} \mathrm{b}$. w. for $\mathrm{Cd}$, respectively.

According to USEPA standards [11], an oral reference dose $\mathrm{R}_{\mathrm{FD}}$ Cd element is $0.001 \mathrm{mg} / \mathrm{kg} /$ day. The average adult body weight $\mathrm{W}_{\mathrm{AB}}$ is $60 \mathrm{~kg}$. The average daily amount of fish for human consumption is $36 \mathrm{~g}$. The health risk factor of $0.004, \mathrm{Cd}$ is much less than 1 , indicating that $\mathrm{Cd}$ exposed populations had no significant health risk.

\section{ACKNOWLEDGEMENT}

This research was financially supported by Fishery Bureau of Tianjin Youth Science and Technology Innovation Project (J-2014-08); Tianjin agricultural scientific and technological achievements and to promote the project (201 304 150); the projects of Seafood aquaculture technology research and demonstration in Artificial reefs (1411).

\section{REFERENCES}

[1] Alinnor IJ, Obiji IA. Assessment of trace metal composition in fish samples from Nworie River. Pakistan J Nutri. 2010;9(1):81-5.

[2] Sani U. Determination of some heavy metals concentrations in the tissues of tilapia and catfishes. Biokemistri. 2011;23(2):73-80.

[3] WHO. Malathion in drinking water. Background Document for Preparation of WHO guidelines for drinking water quality. Geneva: World Health organization (WHO/SDE/WSH/03.04/103); 2003. 
[4] De TK, De M, Das S. Level of heavy metals in some edible marine fishes of mangrove dominated tropical estuarine areas of Hooghly River, North East Coast of Bay of Bengal, India. Bull Environ Contam Toxicol, 2010, 85:385-390

[5] Di Leo A, Cardellicchio N, Giandomenico S. Mercury and methylmercury contamination in Mytilus galloprovincialis from Taranto Gulf (Ionian Sea, Southern Italy): Risevaluation for consumers. Food Chem Toxicol,2010, 48:3131-3136.

[6] EFSA Scientific opinion on lead in food (request $\mathrm{N}$ EFSA-Q-2007-137) (adopted on 18 March 2010) EFSA panel oncontaminants in the food chain (CONTAM). EFSA J, 2010, 8:1570

[7] Ginsberg GL, Toal BF. Quantitative approach for incorporating methylmercury risks and omega-3 fatty acid benefits in developing species-specific fish consumption advice. Environ HealthPerspect,2009, 117:267-275

[8] Wanghui Yan sediments geochemical study of Bohai Bay [D]. Chinese Academy of Geological Sciences, 2014.

[9] State Oceanic Administration, marine monitoring GB / T 12763.6-2007 [S] Beijing: China Standard Press.

[10] Administration of Quality Supervision, Inspection and Quarantine of People's Republic of China. Fresh sea fish quality standards GB / T 18108-2008 [S].Beijing: Standardization Administration of China.

[11] Zhang to Lancang River water and sediment and heavy metals in fish distribution and ecological risk assessment [D]. Yunnan University, 2015.

[12] Heavy Metal Pollution Liu Jinhu multiphase media. Laizhou Bay and its transfer and biological food chain (network) amplification [D]. Institute of Oceanology, 2013.

[13] The quality and safety of agricultural products Aquatic Safety Requirements GB 18406.4-2001. 